\title{
L'objectivació de la identitat europea en els tractats i en les declaracions de les institucions europees
}

\author{
Lluís Català Oltra \\ UNIVERSITAT D'ALACANT \\ lluis.catalafagcloud.ua.es \\ ORCID. 0000-0001-9426-6640
}

Rebut: 25/07/2019

Acceptat: 16/07/2020

\section{RESUM}

En les últimes dècades els conceptes de «nació» i «identitat territorial» han patit una transformació en els àmbits polítics i acadèmics, amb un canvi de conceptes ètnic-culturals tradicionalment dominants a uns altres de caràcter políticocívic. Els primers tendeixen a definir la identitat a través d'elements objectius (llengua, història, territori, cultura, tradicions, etc.) mentre que els segons adopten un enfocament més subjectiu (bàsicament, «la voluntat de ser»). En aquest treball aprofundim en aquesta transformació en el cas de la identitat europea. Per a això, proposem un enfocament qualitatiu i evolutiu que utilitza textos promoguts per la UE (declaracions i tractats), en els quals la identitat juga un paper rellevant. Realitzem una anàlisi de contingut que selecciona aquells elements que han arribat a objectivar la identitat europea (i, com a contrast, mirem aquells elements que incideixen en la identitat dels Estats membres). Si bé identifiquem un avanç en la concepció políticocivil com a reflex de la tendència general, encara queden elements objectius d'orientació cultural en els textos del segle XXI. Això reflecteix la necessitat de presentar públicament una identitat en construcció com una cosa naturalitzada i com a part d'una realitat construïda a través dels temps. Per a Europa els conceptes amb major presència són «identitat europea» (més freqüent en informes i declaracions breus), «cultura europea» i «patrimoni comú europeu» (més comú en els tractats). Aquests conceptes, en un cert sentit, reflecteixen una realitat determinada.

Paraules clau: identitat europea, Unió Europea, nació, construcció europea.

ABSTRACT. The objectification of European Identity in the treaties and in European institutions' declarations

In recent decades the concepts of "nation" and "territorial identity" have undergone a transformation in terms of politics and academia, with a shift from traditionally dominant ethno-cultural concepts to others of a political-civic nature. The former tend to define identity through objective elements (language, history, territory, culture, traditions, etc.) while the latter take a more subjective approach (basically, 'the will to be'). In this paper, we delve into this transformation in the case of European identity. To this end, we propose a qualitative and evolutionary approach that uses texts promoted by the EU (declarations and treaties), in which identity plays a relevant role. We carry out a content analysis that singles out those elements that have come to objectify the European identity (and, as a contrast, we look at those elements bearing on the identity of the Member States). While we identify an advance in the political-civil conception as a reflection of the general trend, culturally-oriented objective elements still remain in 21 st Century texts. This reflects the need to publicly present an identity in construction as something naturalised, and as part of a reality built through the ages. For Europe the concepts with greatest presence are "European identity" (more frequent in reports and brief declarations), "European culture" and "common European heritage" (more common in the treaties). These are concepts that, in some sense, reflect a given reality.

Keywords: European identity, European Union, nation, European construction. 


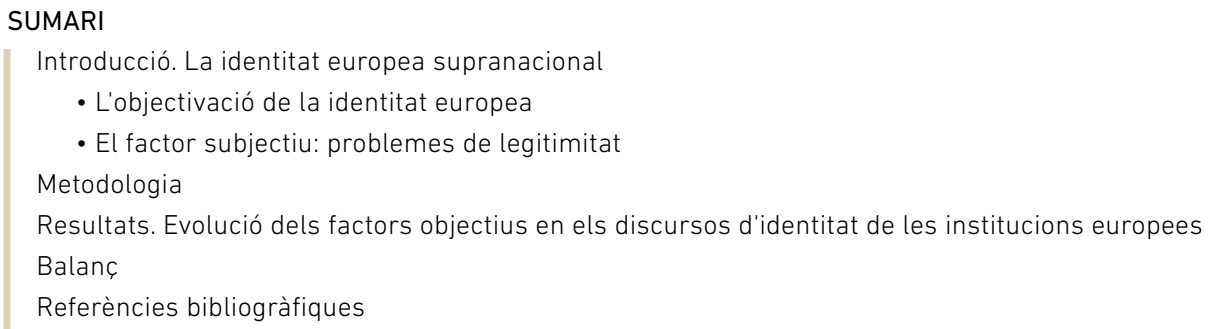

Autor per a correspondència / Corresponding author: Lluís Català Oltra. Universitat d'Alacant. Campus de Sant Vicent del Raspeig, s/n. 03690 Sant Vicent del Raspeig.

Suggeriment de citació / Suggested citation: Català Oltra, LI. (2021) L'objectivació de la identitat europea en els tractats $i$ en les declaracions de les institucions europees. Debats. Revista de cultura, poder i societat, 135(1), 127-143. DOI: http://doi.org/10.28939/iam.debats.135-1.6

\section{INTRODUCCIÓ. LA IDENTITAT EUROPEA SUPRANACIONAL}

En les últimes dècades, el nacionalisme etnocultural s'ha desacreditat cada vegada més, mentre que al mateix temps els enfocaments d'identitat política i cívica han anat guanyant acceptació (veure Català, 2012: 325-336). La concepció de la identitat europea ha experimentat una transformació des d'enfocaments d'orientació culturalista (en els quals s'ha intentat objectivar la identitat comuna dels europeus) a formulacions que alguns diuen «republicanes» (però que, seguint la lògica del nacionalisme, podrien encaixar dins de l'àmbit cívic-polític), i fins i tot les que impliquen una renúncia parcial a l'objectiu de la identitat europea. ${ }^{\mathbf{A}}$ Aquest article, que adopta un enfocament qualitatiu des d'una perspectiva històrica, pretén revelar aquesta trans-

1 Els conceptes que tendeixen a objectivar la identitat són de caràcter etnocultural, mentre que els que es basen en elements subjectius són més de caràcter políticocívic (veure Català, 2012). Els conceptes políticocívics estan vinculats a trets adquirits, mentre que els conceptes etnoculturals estan més vinculats als innats (veure Westle, 2016), encara que aquesta última dicotomia no s'aborda en aquest article. formació hipotètica i, al mateix temps, mostrar els obstacles per a crear una identitat europea, una de les prioritats «no econòmiques» de la UE en diferents moments. Això, al seu torn, permet concretar amb major precisió l'autodefinició de la identitat europea elaborada pels arquitectes del «Projecte Europeu» i que traça plans per a construir aquesta identitat.

Com a primer pas en el desenvolupament argumentari que seguirem, intentarem determinar en quina mesura es pot equiparar la identitat europea a una identitat nacional. Per a nosaltres, en la línia de combinar factors objectius i subjectius, com ja feren Hroch (1996) o Gellner (1983), la nació serà: (1) una comunitat amb un origen i història comunes (a vegades envoltats d'una necessària mística); (2) un territori d'adscripció; (3) una cultura compartida (incloent-hi elements que en alguns casos són determinants com l'idioma, els costums, les tradicions, els estils de vida, la religió, etc.), i que pot haver tingut l'experiència d'alguna mena de formació o institució política a la qual estan/estaven vinculats tots els membres, que, en qualsevol cas, reconeixen la comunitat com una evidència social basada en 
l'homogeneïtat interna que proporcionen els trets comuns (Català, 2012).

La identitat europea és la que es genera a partir de la supranació basada en el continent europeu i, com una identitat nacional, combina tant elements objectius, com a subjectius, encara que, a causa de l'escassa trajectòria com a realitat objectivada i recognoscible pels seus ciutadans, genera en aquests una adhesió limitada (Català i Nieto, 2018).

\section{L'objectivació de la identitat europea}

En primer lloc, cal determinar si els factors objectius (la primera part de la definició citada anteriorment) tenen sentit en el cas de la identitat europea. Fa uns anys, Maryon McDonald (1999: 78; veure també Delanty, 2003; Innerarity, 2013) va destacar les dificultats d'aquest repte de la següent manera:

1. El pack «cultura-historia-poble-territori» que ha utilitzat tradicionalment el nacionalisme no és fàcilment transferible a Europa i, per tant, és complicat que resulte convincent.

2. Les nacions s'han anat construint progressivament, en alguns casos al llarg dels segles, permetent un major acomodament dels elements d'identificació. La curta vida de la UE denota artificialitat, la qual cosa fa que la construcció ad hoc siga encara més evident.

3. El pack del nacionalisme està vinculat a unes certes tradicions i creences que no es corresponen amb un temps actual de diversitat i de relativisme.

4. Aquest antic pack, en fi, assumeix que les identitats són monolítiques i que les cultures són homogènies; no obstant això, les identitats són contextuals, relacionals i canviants (cosa que s'està tornant cada vegada més clara).

Assumint en gran mesura aquestes raonables objeccions, considerem, com Popa (2016: 11), que estem parlant de dues identitats (l'europea-supranacional i la nacional dels Estats membres) la interacció dels quals, ja siga competint o complementant-se, prescriu el seu abordatge en un mateix pla. La pugna hegemònica entre les elits europeistes i alguns dels Estats membres, aguditzada precisament a partir de l'intent de crear una Constitució europea en 2004 primer, i després, per la crisi financera, planteja aquesta necessitat en un moment en què el projecte europeu està sent desafiat de manera evident.

Ja hem assenyalat les dificultats per a precisar els factors que objectiven la identitat europea (Català i Nieto, 2018). En síntesi, a Europa li manca una història única i exclusiva, a més de precedents polítics clars que proporcionen un sentit compartit de pertinença europea; el territori està en constant canvi i debat; no existeix una identitat basada en una tradició cultural clarament definida; com a part d'això, no existeix un llenguatge únic que puga facilitar el desenvolupament d'una cultura pública comuna i el cristianisme no funciona com a nucli clar i unificador; els símbols europeus estan pendents de consolidació; i finalment, no hi ha un «altre» recognoscible per a tota Europa més enllà de les difuses delimitacions continentals.

No obstant això, les dificultats per a objectivar una identitat europea no són molt diferents de les que van afrontar els Estats nació en el passat (i fins i tot en l'actualitat), i s'han resolt a força d'obviar determinats fets, modificar-ne uns altres, explicar-los d'una manera determinada, emfatitzar els elements pertinents, etc. (Hobsbawm i Ranger, 1998). Per tant, amb totes les reserves necessàries, assumim que hi ha elements, més o menys difusos, que ajuden a objectivar Europa i la seua identitat.

\section{El factor subjectiu: problemes de legitimitat}

Les mateixes publicacions de la UE plantegen la Unió Europea com un projecte que, almenys en teoria, naix dels lloables objectius de previndre nous enfrontaments entre Estats i promoure la cooperació i la democràcia. No obstant això, l'entitat embrionària (Comunitat Europea del Carbó i de l'Acer - CECA), i la praxi des de llavors, així com el marc legal des- 
plegat fins hui, no poden ocultar la servitud de la UE envers els mercats, l'eixamplament dels quals i la creació de les millors condicions per al gran capital europeu han sigut els motors del desenvolupament jurídic-institucional continental (Etxezarreta, 2008: 123; Balanyà et ál., 2002). Paral-lelament, tampoc es pot subestimar el component de pugna ideològica amb el model polític que representava l'URSS.

No obstant això, després de l'excessiu èmfasi inicial en el vessant econòmic, en l'impuls al mercat únic i a la lliure circulació de mercaderies (i més tard també de persones), es va sentir la necessitat d'acostar la UE a la ciutadania, era pertinent la creació d'un embolcall de legitimació democràtica que havia de servir per a atraure adhesions a la idea d'Europa i aproximar-la a les seues intencions originals. Aquesta necessitat va créixer a mesura que la UE s'expandia, les enquestes van confirmar el descontentament dels europeus amb aquest projecte (Fligstein, 2009) i anava circulant l'estigma de l'«Europa dels mercaders», que no va poder mitigar el Tractat de Maastricht. De fet, per a explicar la primacia d'una lògica liberal de funcionament recolzada en l'economia, la burocràcia i la llei, Přibáň (2009: 45-46; veure també Hernández i Ramiro, 2016) introdueix una espècie d'oxímoron: la «política de despolitització», que en realitat és una actualització del lema il-lustrat «tot per al poble, però sense el poble». S'ha pretés neutralitzar els conflictes polítics a través de l'entramat legal i un nivell acceptable de benestar econòmic, però escàs desenvolupament democràtic de les institucions europees.

Per tant, la idea d'Europa o de la supranació europea com a entitat generadora d'una identitat territorial amb destacables sentiments d'adhesió està encara lluny de cristal-litzar, com hem apuntat en un altre treball (Català i Nieto, 2018: 28-37). La identitat continua sent un supòsit, perquè el fet de «ser europeu queda sense identificar» de manera precisa (Friese, 2004: 110), almenys de moment. A més, continua prevalent l'òptica nacional de cadascun dels Estats membres i no hi ha un foment decidit a la idea d'una «supranació» europea. S'insisteix en la promoció dels valors democràtics, la bondat de la cooperació i la història «comuna», però sense qüestionar la primacia de les identitats nacionals. Això es reflecteix en les dificultats per a aprovar el Tractat de Lisboa: un tractat que hauria d'haver significat un pas endavant per a la Unió però que en canvi és més recordat per la reeixida oposició d'alguns dels seus membres (amb la culminació del Brexit) que per la seua transcendència i projecció a futur.

\section{METODOLOGIA}

Prenent com a punt de partida la Comunitat Europea del Carbó i de l'Acer (1951), les institucions europees han elaborat un gran nombre de documents oficials. Lògicament, ens interessen aquells que puguen reflectir la forma en què aquestes institucions projecten la identitat europea. A partir de les aportacions de diversos autors (Clerc, 2014; Guth i Nelsen, 2014; Bekemans, 2012; Innerarity i Acha, 2010; Moes, 2008) i una exploració prèvia, entenem que, entre els documents d'una certa rellevància, aquells que poden mostrar millor l'evolució de posicions polítiques oficials en relació a la identitat europea són el Tractat de París (1951), la Declaració sobre la identitat europea (1973), l'Informe Tindemans (1975), l'Informe del Comité Adonnino (1985), el Tractat de la Unió Europea-Maastricht (1992), la Declaració de Laeken (2001), el Tractat pel qual s'estableix una Constitució per a Europa (2004) i el Tractat de Lisboa (2007).

Es van explorar altres documents, inclòs el Tractat constitutiu de la Comunitat Europea de Defensa (1952), que no modificà les disposicions del Tractat de París i no entrà en vigor; els Tractats de Roma (1957) pels quals es constituïen les Comunitats Europees; el Tractat de Fusió o de Brussel-les (1965), que va sorgir per a aglutinar les diferents comunitats europees; l'Acta Única Europea (1986), que marca el començament d'una Europa sense fronteres però que és principalment de caràcter econòmic; el Tractat d'Amsterdam (1997), que no suposa un canvi fonamental respecte a Maastricht i implica 
sobretot ampliacions relacionades amb la justícia i la seguretat; o el Tractat de Niça (2001), que tampoc modifica a penes el Tractat de Maastricht i va servir per a preparar el camí per a la gran ampliació a l'est. Una anàlisi de contingut inicial d'aquests últims textos va revelar que no hi són presents conceptes clau relacionats amb la identitat (en la majoria dels casos perquè els documents se centren principalment en qüestions econòmiques).

Aquest no és el cas dels tractats finalment inclosos (París, Maastricht, Constitucional i Lisboa), ja que, si bé van ser bastant generalistes, també han inclòs creixentment (amb l'avanç del procés d'integració) elements que feien referència a la identitat europea. El cas és diferent per als altres quatre documents revisats: són més breus i corresponen a declaracions i informes ordenats per la Comissió Europea en diferents etapes (sobretot durant el període 1973-1985), fruit de la preocupació per oferir una imatge de la construcció europea menys lligada a l'economia i que començara a connectar amb uns ciutadans que ja en les primeres enquestes es mostraven majoritàriament indiferents a una Europa poc present en les seues vides (Fligstein, 2009). Aquests textos contenen una major proporció de conceptes relacionats amb la identitat $i$, lògicament, més encara en el cas de la monogràfica Declaració sobre la identitat europea. En qualsevol cas, no necessitem homogeneïtat en el volum de paraules ni en la naturalesa dels textos, atés que el nostre objectiu no és determinar quin conté més referències a la identitat europea, sinó més aviat observar l'evolució de la conceptualització de la identitat europea.

Per a l'anàlisi d'aquests textos s'han seleccionat diferents lexemes que, a partir de la bibliografia consultada i de l'anàlisi semiòtica, entenem que poden representar l'objectivació de la identitat europea: civilització, cultura, identitat, herència, religió, cristiandat, història, ètnia, tradició, destí, símbol, societat i realitat (es van buscar aquests termes i les seues arrels lèxiques). Evidentment, els lexemes que es refereixen explícitament a Europa o la UE són part de la nostra anàlisi (els textos de la UE alternen tots dos vocables. Veure Taula 1). Això s'ha contrastat en els fragments textuals on els lexemes han aparegut (per exemple, herència cultural d'Europa, símbols de la UE, societat europea, tradició religiosa dels europeus, etc.). Al mateix temps, aquests conceptes $s^{\prime}$ han rastrejat en els textos per als Estats membres o realitats territorials diferents a Europa (Taula 2) perquè servisquen de contrast. Mitjançant l'aplicació de codificació del programari d'anàlisi qualitativa Atlas.ti, es van localitzar les arrels dels vocables en els textos. Posteriorment es va comprovar que el significat era l'adequat, ja siga per a l'objectivació d'Europa o per a la dels Estats membres. Després d'aquest sedàs de significat, es van construir taules de freqüència que permeten l'anàlisi de contingut.

Com reporten Hopkins i King (2010) o Gattermann, Högenauer i Huff (2016), és habitual i pertinent l'anàlisi textual de documents governamentals com a forma d'aproximació a les polítiques i fins i tot la ideologia dels qui dirigeixen les institucions. No obstant això, ha sigut poc freqüent treballar textos dels organismes oficials europeus (veure, per exemple, Wisniewski, 2013; o Waldschmidt, 2009), i és encara més infreqüent treballar amb els tractats i declaracions que hem seleccionat. El nostre enfocament és, per tant, nou, i ens permet arribar al nucli de les polítiques identitàries oficials de la UE per a delimitar les vies per les quals discorre en el marc de la dicotomia objectiu-subjectiu.

\section{RESULTATS. EVOLUCIÓ DELS FACTORS OBJECTIUS EN ELS DISCURSOS D'IDENTITAT DE LES INSTITUCIONS EUROPEES}

Seguint amb allò que s'ha exposat, aquest treball analitza l'evolució dels elements objectius en el discurs oficial de les institucions europees i, en última instància, comprova la seua vigència en els documents d'aquest mil.lenni. De l'anàlisi de contingut sorgeixen les taules de freqüències següents: 
Taula 1 Presència de conceptes que objectiven Europa o la UE en una selecció de documents oficials de les institucions europees

\begin{tabular}{|c|c|c|c|c|c|c|c|c|c|c|c|c|c|}
\hline 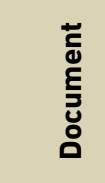 & 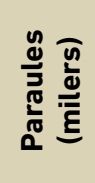 & 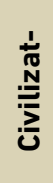 & $\frac{1}{3}$ & $\begin{array}{l}\text { 든 } \\
\text { 음 }\end{array}$ & 흔 & $\frac{\text { ’음 }}{: \frac{0}{0}}$ & $\frac{1}{\frac{1}{0}}$ & $\frac{\dot{1}}{\text { ह }}$ & 로 & 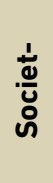 & 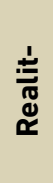 & $\frac{1}{\overleftarrow{6}}$ & 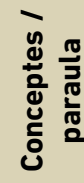 \\
\hline TP & 20 & 0 & 0 & 0 & 0 & 0 & 0 & 0 & 1 & 0 & 0 & 1 & 0,50 \\
\hline DEI & 3 & 2 & 0 & 7 & 1 & 0 & 1 & 0 & 0 & 1 & 0 & 12 & 45,80 \\
\hline TR & 16 & 1 & 1 & 7 & 3 & 0 & 1 & 0 & 6 & 5 & 1 & 25 & 16,11 \\
\hline ACR & 7 & 0 & 2 & 2 & 0 & 0 & 0 & 1 & 0 & 0 & 0 & 5 & 7,19 \\
\hline TEU & 104 & 0 & 3 & 1 & 2 & 0 & 1 & 0 & 0 & 0 & 0 & 7 & 0,67 \\
\hline LD & 5 & 0 & 0 & 0 & 0 & 0 & 1 & 0 & 0 & 0 & 1 & 2 & 4,40 \\
\hline TCE & $155 a$ & 0 & 5 & 0 & 5 & 1 & 1 & 1 & 1 & 1 & 0 & 15 & 0,97 \\
\hline $\mathrm{TL}$ & 158 & 0 & 2 & 0 & 2 & 1 & 0 & 2 & 0 & 1 & 0 & 8 & 0,50 \\
\hline TOTAL & & 3 & 13 & 17 & 13 & 2 & 5 & 4 & 8 & 8 & 2 & 75 & \\
\hline
\end{tabular}

(a) Sense considerar les declaracions de l'Acta Final, que impliquen esmenes i modificacions del Tractat original. Llegenda: TP = Tractat de París (1951), DEI = Declaració sobre la identitat europea (1973), TR = Informe Tindemans (1975), ACR = Informe del Comité Adonnino (1985), TEU = Tractat de la UE (1992), LD = Declaració de Laeken (2001), TCE = Tractat pel qual s'estableix una Constitució per a Europa (2004), TL = Tractat de Lisboa (2007).

Taula 2 Presència de conceptes que objectiven els Estats membres de la UE o es refereixen a realitats territorials diferents de la UE en una selecció de documents oficials de les institucions europees

\begin{tabular}{|c|c|c|c|c|c|c|c|c|c|c|c|c|c|}
\hline & 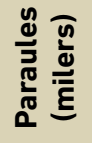 & $\frac{\stackrel{1}{N}}{\stackrel{N}{\frac{N}{3}}}$ & $\stackrel{1}{3}$ & 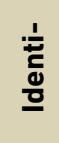 & 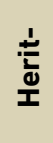 & $\frac{\dot{o}}{\frac{\sigma}{0}}$ & $\frac{1}{\frac{1}{n}}$ & 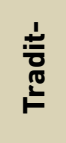 & $\frac{1}{\frac{1}{4}}$ & 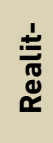 & $\begin{array}{l}\text { 亡́ } \\
\text { Ĺ }\end{array}$ & $\begin{array}{l}\text { 它 } \\
\text { 암 }\end{array}$ & 它总竞 \\
\hline TP & 20 & 1 & 0 & 0 & 0 & 0 & 0 & 0 & 0 & 0 & 0 & 1 & 0,50 \\
\hline DEI & 3 & 0 & 3 & 1 & 1 & 0 & 2 & 0 & 0 & 0 & 0 & 7 & 26,72 \\
\hline TR & 16 & 1 & 3 & 0 & 0 & 0 & 0 & 1 & 0 & 0 & 0 & 5 & 3,22 \\
\hline ACR & 7 & 0 & 0 & 0 & 0 & 0 & 0 & 0 & 0 & 0 & 0 & 0 & 0,00 \\
\hline TEU & 104 & 0 & 3 & 4 & 0 & 0 & 1 & 2 & 0 & 0 & 0 & 10 & 0,96 \\
\hline LD & 5 & 0 & 1 & 1 & 0 & -1 & 1 & 2 & 0 & 0 & -1 & 8 & 17,58 \\
\hline TCE & $155 a$ & 2 & 15 & 3 & 1 & 1 & 1 & 10 & 1 & 1 & 0 & 35 & 2,26 \\
\hline TL & 158 & 0 & 4 & 1 & 0 & 0 & 0 & 8 & 0 & 1 & 0 & 14 & 0,88 \\
\hline Totals & & 4 & 29 & 10 & 2 & 2 & 5 & 23 & 1 & 2 & 1 & 80 & \\
\hline
\end{tabular}

(a) Sense considerar les declaracions de l'Acta Final, que impliquen esmenes i modificacions del Tractat original.

Llegenda: TP = Tractat de París (1951), DEI = Declaració sobre la identitat europea (1973), TR = Informe Tindemans (1975), ACR = Informe del Comité Adonnino (1985), TEU = Tractat de la UE (1992), LD = Declaració de Laeken (2001), TCE = Tractat pel qual s'estableix una Constitució per a Europa (2004), TL = Tractat de Lisboa (2007).

Nota: els valors negatius indiquen conceptes utilitzats amb una càrrega negativa, oposats al projecte de la UE.

Font: elaboració pròpia. 
En termes absoluts, l'Informe Tindemans (TR), el Tractat Constitucional (TCE) i la Declaració sobre la Identitat Europea (DEI) són els textos en els quals aquests conceptes tenen més presència per a la objectivació d'Europa. En el cas de l'objectivació dels Estats membres, destaca clarament el TCE, seguida dels tractats de Lisboa (TL) i de la Unió Europea (TEU). Els resultats són una mica diferents si es relativitzen en funció del total de paraules i, d'aquesta manera, passen a sobreeixir els textos curts amb un alt pes d'aspectes identitaris, molt per damunt la DEI, però també el TR i l'Informe del Comité Adonnino (CAR) en el cas d'Europa, i la DEI i la Declaració de Laeken (LD) per als Estats membres.

En el conjunt dels textos, per a Europa els conceptes que major presència tenen són «identitat europea» (més freqüent en els informes i declaracions breus), «cultura europea» $i$ «herència comuna europea» (amb més presència en els tractats); mentrestant, per als Estats membres, destaquen molt per damunt de la resta «cultura» $\mathbf{i}$ «tradició dels Estats membres», en molts casos citats conjuntament per a subratllar que cal respectar la diversitat característica de la UE. «Tradició» no apareix com a concepte per a objectivar Europa, però ja hem comprovat que és molt freqüent per a objectivar els Estats membres, de la mateixa manera que «herència» 0 «destí » a penes són utilitzats per a objectivar els Estats membres, però la Comissió recorre sovint a ells quan es tracta de la identitat europea. Globalment, s'han localitzat 75 presències de conceptes que objectiven Europa i 80 que objectiven sobretot els Estats membres, com a reflex del delicat equilibri que la Comissió Europea intenta mantindre i que va tindre el seu moment de major tensió en la redacció del text constitucional de 2004 (posteriorment rebutjat per països que van considerar que s'havia anat massa lluny en el desenvolupament competencial d'una carta magna europea que, a més, consagrava determinats símbols a l'estil dels que exhibeixen els Estats nació).

A partir de la identificació i quantificació de la presència d'aquests conceptes mitjançant anàlisis de contingut, ens plantegem una aproximació qualita- tiva i evolutiva dels documents per a determinar fins a quin punt es mantenen elements que objectiven Europa com a entitat supranacional.

La idea d'Europa i d'una unió entre pobles per a preservar la pau i col-laborar en el progrés prové de la Il-lustració, i específicament amb els treballs de Kant i Rousseau i després amb el encunyament del terme «Estats Units d'Europa» per part de Victor Hugo (Granja i Charpenel, 2014; Clerc, 2014: 10). En contra dels desitjos dels seus precursors, la idea d'un federalisme europeu en la línia del que ja s'havia format a Amèrica del Nord, xocava amb la formació i assentament d'un món de nacions (Estat), que tindria la seua versió més definida en la primera meitat del segle XX (Hobsbawm, 1992: 85-152). Però en aquell moment i encara que fora en un segon pla, l'europeïsme ja buscava obrir-se pas davant l'Estat nació.

És a partir de la reconstrucció que va succeir a la Segona Guerra Mundial quan es tornen a explorar aquestes vies. Com a teló de fons, els desitjos de pau i reconciliació, però també la necessitat del capital (senyaladament l'estatunidenc) de donar forma a un mercat estable en el vell continent, que afegia, al seu torn, la pugna ideològica amb el bloc comunista de la part oriental.

Un dels personatges amb més protagonisme en la contesa mundial, Winston Churchill, és dels primers a insistir en la necessitat de cooperació i d'encaminar els Estats europeus cap a una espècie de federació. D'un discurs que dona en aquesta línia en la Universitat de Zuric (1946), cal destacar també la concepció essencialista i supremacista que té d'Europa: «...és el bressol de totes les races originàries del món. És el bressol de la fe i l'ètica cristianes. És l'origen de quasi totes les cultures, arts, filosofies i ciències» (Popa, 2016: 13). Malgrat la presència d'aquests elements que ell entén com a objectius, invoca un «acte de fe» col-lectiu («en el que hi participen conscientment milions de famílies que parlen moltes llengües»; Popa, 2016: 14) per a donar lloc a les institucions i la identitat europea, com a mesura per a previndre noves catàstrofes. 
Això és el que impulsen actors com el ministre d'afers exteriors francés d'ascendència alemanya Robert Schuman, però inicialment de manera gradual i amb objectius de tipus econòmic, sense espai per a la creació d'una comunitat política. De tota manera, en el preàmbul del Tractat de París (1951), que va establir la Comunitat Econòmica del Carbó i de l'Acer, s'avança que la persecució d'interessos econòmics podia suposar «la base per a una comunitat més àmplia i profunda», idea sobre la qual s'insisteix també en els Tractats de Roma, constitutius de la Comunitat Econòmica Europea-CEE (Bekemans, 2012). En aquest primer text es parla d'un «destí comú» que han de perseguir les institucions polítiques europees, però tampoc hi ha moltes més referències per a objectivar Europa. Es parla de «civilització» però amb un caràcter més universal, considerant allò que la construcció europea podria aportar al conjunt de la humanitat.

En el pla agencial, és convenient puntualitzar que en els moments inicials, la integració europea és un projecte de la democràcia cristiana catòlica ${ }^{2}$ secundat fins i tot pel Vaticà. Els líders protestants, en canvi, van mostrar des de l'inici reticències de base nacional, continuant la tradició d'enfrontament al projecte «universalista» de la jerarquia catòlica que donà peu a les diferents branques amb vincles palesament nacionals (anglicans, luterans, calvinistes...). La variable religiosa ha tingut després, des de les primeres enquestes d'opinió d'abast europeu fins als nostres dies, una capacitat explicativa rellevant respecte al nivell d'adhesió ciutadana al projecte europeu: els individus catòlics (i més encara els practicants) han sigut els que més suport han donat a la integració europea, enfront de protestants o agnòstics (i en general amb el major rebuig registrat pels protestants l'església dels quals està nacionalment formada). Només els catòlics conservadors dels països de l'est recentment adherits i en alguns moments Irlanda escapen a aquesta tendència (Guth i Nelsen, 2014: 1-3).

2 Els que es consideren pares fundadors del que hui és la UE (Konrad Adenauer, Alcide de Gasperi, Jean Monnet i Robert Schuman) eren democratacristians i devots catòlics.
Ja des del començament de la CEE es feia referència en declaracions i diferents documents a una «herència cultural comuna», que havia de sumar-se als valors democràtics compartits. S'adopten, doncs, «els mecanismes utilitzats tradicionalment pels Estats per a crear aquesta consciència d'identitat compartida, com pot ser la hipostatització d'una herència, una història i una cultura comuna o una certa visió etnocentrista de la pròpia cultura» (Innerarity i Acha, 2010: 73-74). Segons Keating (2009: 141; citat en Innerarity i Acha, 2010: 74), en aquesta etapa es poden identificar indicis de la cerca d'una «nació europea», però no es parla de «ciutadania europea» (Máracz i Versteegh, 2010: 165), no opera una concepció cívica de la nació sinó, com hem avançat, més aviat «cultural». Malgrat aquesta opinió, que comparteixen diferents autors, potser sobre la base de la manera d'entendre la identitat en aquella època (els fragments de Churchill en són un bon exemple), els textos inicials de les institucions europees no reflecteixen de manera clara aquesta concepció, perquè la políticocívica també té un pes notable.

En els setanta, quan s'estava produint la primera expansió (Dinamarca i el Regne Unit), «la identificació dels ciutadans amb Europa, com a base de la seua legitimitat» comença a ser una preocupació (Innerarity i Acha, 2010: 74). Això té un reflex molt explícit en la Declaració sobre la identitat europea (Comissió Europea, 1973), en la qual s'incorpora aquest concepte, sobre la base $\mathrm{d}^{\prime}$ «una herència comuna i uns valors polítics compartits» i a fi de reforçar la cohesió interna i assegurar la viabilitat del projecte europeu. Són elements que ja es volen integrar al sistema educatiu dels països membres, buscant establir vincles afectius i, en síntesi, una comunitat culturalment definida (Innerarity i Acha, 2010: 74; Clerc, 2014: 8; Guth i Nelsen, 2014: 5). Els elements cívics són presents en els trajectes educatius, però potser encara subordinats als històrics i culturals.

De tota manera, quan es redacta la Declaració sobre la identitat europea (DIE) tenim una CEE encara en bolquers, amb ressorts polítics molt limitats 
la primacia evident de l'Estat nació (si no haguera sigut d'aquesta manera, el Regne Unit ni s'haguera plantejat incorporar-s'hi). Això implica que la prudència domina en aquesta Declaració, d'aquí ve que sí que es parle repetides vegades d'una «varietat de cultures» en el marc d'una «civilització europea comuna», però que es destaque, per damunt de tot, la preservació de «valors jurídics i polítics» $\mathrm{i}$ la salvaguarda de «principis» com la democràcia representativa, l'Estat de dret, la justícia social o els drets humans, que han de ser la base per a conformar la identitat europea. També es confia que les institucions i polítiques comunes vagen calant en la ciutadania per a formar «part integrant de la identitat europea». Per tant, estem davant una arquitectura identitària que combina les perspectives etnocultural i políticocívica, en la qual no hi ha objeccions a l'hora d'emprar conceptes com «civilització europea», però en la qual es té clar que la construcció políticoinstitucional present i futura ha de ser la part més rellevant de la identitat europea futura. Així, es diu explícitament que

[...] definir la identitat europea implica: revisar l'herència, interessos i obligacions comunes dels Nou, així com el grau d'unitat assolit fins ara dins de la Comunitat; avaluar fins a quin punt els Nou actuen junts en relació a la resta del món i les responsabilitats que se'n deriven; i prendre en consideració la naturalesa dinàmica de la unificació europea.

Per tant, es combina allò històric-cultural (herència) amb alló políticocívic (interessos i obligacions, procés de construcció), a més d'incloure una referència a la dinàmica alteritat-ipseïtat (món-Europa), que és essencial en la conformació de qualsevol identitat (encara que en altres paràgrafs es parla, per exemple, de l'herència compartida amb els Estats Units, en una ampliació atlantista del focus civilitzatori).

Aquella declaració va ser un dels punts de partida del desenvolupament polític de la CEE, i un any més tard, en la cimera de París, entre altres avanços, es fan els passos per a l'elecció mitjançant sufragi del
Parlament europeu, que es faria efectiva en 1979 i enfortiria el bagatge simbòlic de les Comunitats Europees. Es donava, per tant, l'impuls primitiu a la «Europa dels ciutadans», que havia d'activar el sentiment de pertinença a la comunitat compartida.

També és de gran importància l'Informe Tindemans (1975), encapçalat per un altre democratacristià, com a gran part de les iniciatives de les primeres dècades de la integració europea (Guth i Nelsen, 2014: 5), que és potser l'antecedent més visible de la Unió Europea fins als moments previs a Maastricht. Tindemans proposa una «Europa dels ciutadans» que incloga l'eliminació de fronteres, unificació de passaports, un espai educatiu comú, l'enfortiment del parlament europeu, la unió monetària, etc. També és un text on hi ha una presència important d'elements objectius. Per exemple, igual que en la DIE, es dona per feta una civilització europea (encara que també s'apunte que forma part d'una civilització més àmplia) o l'existència d'una herència comuna a tots els europeus (que són valors, cultura, una manera d'entendre el món, etc.); així mateix, la identitat europea s'expressa en diversos fragments com una realitat factual, tant per als no europeus com per als propis europeus (realitat que necessita, no obstant això, ser reforçada tant internament com exteriorment). D'altra banda, tot i que s'al.ludeix a una «història de la unificació d'Europa», es considera que aquesta entrava en aquell moment en la seua fase clau i, per tant, era una història bàsicament per construir. Aquest informe destaca, finalment, per assumir insistentment un «destí comú dels europeus» (un destí que, com la identitat, ha d'estar apuntalat per la voluntat dels dirigents i els ciutadans europeus), una «societat europea» (que existeix, però també s'ha de construir en la línia que marquen «els nostres valors») i fins i tot una «realitat europea», per a, de manera agregada, acabar confluint en el que podem entendre com la més evident objectivació multiconceptual de la hipotètica «supranació» europea fins hui.

En 1984, en el cim de Fontainebleau, a més de les mesures econòmiques, la CEE va decidir que calia 
aprofundir en l'acostament al ciutadà i en la creació/ consolidació d'una identitat europea. Per a això es va crear el Comité Adonnino, que seria l'impuls primitiu a l'Europa dels ciutadans i l'informe dels quals parlava explícitament d'«enfortir la imatge i la identitat de la Comunitat» (Adonnino, 2014: 19). Aquell comité va ser el precursor de la bandera, l'himne i el dia d'Europa, elements que suposen la imitació del repertori simbòlic dels Estats nacionals. També es posava èmfasi en la necessitat d'intensificar els contactes transfronterers a diferents nivells (comerç, treball, educació, investigació, cultura...), a progressar en l'aprenentatge de llengües, i un altre tipus de mesures que havien d'ajudar a la construcció del «nosaltres» europeu (Adonnino, 1985; Guth i Nelsen, 2014: 5).

Malgrat aquesta preocupació pel ciutadà i de com d'avançada era la proposta Adonnino per a aquell moment històric, en realitat es va plantejar la creació d'una identitat des de dalt i de manera centralitzada (tot i que convé subratllar que el debat sobre la participació i la legitimitat de les institucions estava lluny d'assolir la intensitat actual).

D'altra banda, en 1988 el Consell d'Europa decideix que els sistemes educatius dels països havien d'adoptar una perspectiva europea per a anar fomentant la idea d'una història i una herència cultural comunes. S'arriben a editar llibres com el de Duroselle (1990), Europe: a history of its peoples (Londres: Viking), que parla d'una història del poble europeu de més de 5.000 anys (Karlsson, 1999: 65). De tota manera, aquesta perspectiva civilizatoria continental venia adoptant-se des d'un temps després de la Segona Guerra Mundial, quan, per exemple, les guerres $\mathrm{d}^{\prime}$ «independència» de gals o germànics «van cedir el seu lloc a la romanització presentada com un procés d'integració europeu i base d'una civilització i cultura comunes» (López Facal, 2010: 13). En general es van desdibuixant les explicacions de la història marcadament nacionals en els llibres de text escolars i va prenent cos un relat comú europeu que té la seua base en la tradició grecoromana, el cristianisme i el sistema feudal de l'Edat Mitjana, el Renaixement, la Il-lustració, la revolució industrial i les revolucions liberals. Aquesta perspectiva integradora, que havia de contribuir a la prevenció dels conflictes entre Estats europeus, va imposar, com a contrapartida, una visió eurocentrista en la qual s'afirma un nosaltres enfront d'un altres asiàtic $o$ africà, que a vegades és invisibilitzat $i$ en altres explicat com a antagonista, d'una manera similar a com l'havien fet anteriorment els desenvolupaments curriculars en clau nacionalista (López Facal, 2010: 14 i 23).

L'inici dels anys noranta, amb la signatura del Tractat de Maastricht com a fita més important (encara que també amb la recent caiguda del Mur de Berlín i la possibilitat d'ampliació cap a l'est), seria un punt d'inflexió en l'aposta per una identitat europea (Moes, 2008: 3). Ja s'estan fent alguns passos per a una unió política i augmenta la preocupació i la investigació sobre la identitat europea, encara que comencen a generalitzar-se aproximacions amb una concepció més instrumental (ciutadana, políticocívica), si es vol, «postnacional», com apunten Innerarity i Acha (2010: 74).

En el Tractat de la Unió Europea (Comissió Europea, 1992), s'avança que la nova institució es funda en els principis de la «llibertat, democràcia, respecte als drets humans i llibertats fonamentals, i la primacia de la llei» (article 6) i es delimita l'estatus legal de la ciutadania europea, que posseeixen els individus de qualsevol dels Estats membres. S'entén com un pas ferm per a incrementar el sentiment de pertinença a partir de fer efectius els valors democràtics, i com un instrument per a potenciar la dimensió interna de l'europeïtat, no únicament la que distingeix la UE de la resta del món. Al marge de l'èxit real en la consecució d'aquests propòsits i encara que aquesta visió políticocívica és la dominant, els treballs per a la redacció del text van evidenciar que una part de l'arc polític entén com a fonamental la tradició cristiana, entre altres elements culturals $i$, per tant, el model «comunitari» (Bekemans, 2012; Tsaliki, 2007: 159) i la seua visió cultural encara tenien una importància no menyspreable. 
La seua insistència es va saldar amb referències a «una herència cultural comuna» $o$ a una «herència cultural de significació europea » que, no obstant això, hauria de ser compatible amb les tradicions culturals dels països membres. També s'assumeix l'existència d'una història dels pobles d'Europa, la que des del 1988 ha de ser contada en els llibres de text en un sentit unitari. Així mateix, hi ha una referència explícita a la identitat europea, però no tant en termes del que Recchi i Salamonska (2014: 512) anomenen «pertinença», sinó més aviat una identitat com a diferència i contrast amb altres territoris en el context internacional. Aquesta idea va més enllà amb l'aclariment que segueix a la referència: «la Unió [ha d'] afirmar la seua identitat en l'escena internacional, en particular a través de la implementació d'una política exterior i de seguretat comunes, incloent el marc eventual d'una política comuna de defensa», i fins i tot amb diferents al-lusions a una «identitat europea de seguretat i defensa». Això i la definició restrictiva de ciutadania és el que ha portat a alguns autors a sentenciar que el TUE «estableix més una base unitària per a l'exclusió, que un conjunt coherent de criteris per a la inclusió» (Tsaliki, 2007: 168), sobre com distingir-nos de la resta del món més que la manera de posar els fonaments perquè les persones confluïsquen en l'espai europeu.

D'altra banda, i al marge dels textos objecte d'estudi, a meitat dels noranta sorgeixen diferents documents molt centrats en la identitat europea que van alimentar el debat conceptual i van tornar a evidenciar que els elements objectius de base cultural continuaven tenint un lloc en la definició de què són els europeus. El primer d'ells és la Carta de la identitat europea (1995), preparat pel lobby dels federalistes europeus a instàncies de l'expresident de la República Txeca, Vaclav Havel, i que, per exemple, entén Europa com una «comunitat de destí», els valors de la qual s'han construït «sobre arrels històriques situades en l'Antiguitat clàssica i la cristiandat, [...] desenvolupades en el Renaixement, el moviment humanista i la Il-lustració», encara que el tipus d'identitat que es planteja ulteriorment està més prop d'una concepció políticocívica.
Un any més tard, la UE celebra una trobada monogràfica sobre la identitat europea a Coïmbra (Jansen, 1999) on també es combinen concepcions de la identitat de tipus cultural i políticocívic. Un exemple de la primera és la que ofereix l'historiador luxemburgués Gilbert Trausch (1999: 26), qui, des de posicions que podríem categoritzar com perennialistes (Smith, 2005), afirmava que les elits europees han reconegut aquesta identitat des de l'Edat Mitjana, encara que s'hagen produït conflictes bèl-lics entre països fins al 1945. Però en aquesta trobada també es parla de "patriotisme constitucional europeu» (Eriksson, 1999: 66) i d’un sentit cívic, en la línia dels temps que van seguir a la caiguda del Mur de Berlín i els seus conflictes de caire ètnic, sense abandonar la idea d'un «nosaltres» constituït oposadament a un «altres» amb interessos en competència (els EUA, Rússia, la Xina, etc.).

Abans del nou mil.lenni, també hem de destacar l'aparició del llibre In from the margins (ETCD, 1997), editat pel Consell d'Europa i que se centra monogràficament en la importància de la cultura per al desenvolupament i per a la formació d'un sistema simbòlic de significació. Com apunta Tsaliki (2007: 160), també subjau en aquest escrit la necessitat de definir la identitat europea sobre la base d'una herència cultural $i$, en un futur, a partir $d^{\prime}$ «una cultura de masses comuna disseminada a través d'un espai europeu integrat de mitjans de comunicació». Es proclama i es posa en valor la diversitat d'Europa, però també se subratlla la seua unitat i especificitat com a impulsora inicial dels valors democràtics.

Tornant als textos objecte d'anàlisi, la Declaració Laeken (2001) és un altre dels rellevants per a entendre la posició oficial de la UE quant a la identitat europea. Signada pel Consell Europeu de Laeken (Bèlgica), va establir les bases per a la Convenció sobre el futur d'Europa posterior (2002-2003), que al seu torn estava encarregada de redactar l'esborrany de la Constitució Europea. En realitat, no destaca pel reforç de la identitat europea enfront de la dels Estats membres, sinó tot el contrari: tal vegada en una mostra de les prevencions que després van entrar en 
joc per a curtcircuitar la Constitució. Es pot apreciar en un dels fragments que millor resumeixen aquest plantejament des d'una òptica marcadament liberal:

En altres paraules, allò que els ciutadans entenen [esperen] és l'obertura a noves oportunitats, no la imposició de més tràmits burocràtics. [...] Millors respostes a assumptes pràctics i no un Superestat europeu o institucions europees persuadint-los sobre cada xicotet aspecte de la seua vida.

En qualsevol cas, com altres textos anteriorment, també se subratlla l'herència comuna dels europeus, però en aquest cas emfatitzant i posant en valor la història del pensament liberal («Europa, el continent dels valors humans, la Carta Magna, la Carta de Drets, la Revolució francesa i la caiguda del Mur de Berlín...»).

Aquesta herència comuna, que culmina en els valors democràtics, és el bagatge identitari que el projecte europeu oposa a les anomenades «forces opositores», entre les quals destaquen el «fanatisme religiós» i el «nacionalisme ètnic». Per tant, es contraposa explícitament allò políticocívic (positiu) a allò etnocultural (negatiu). La Declaració Laeken conclou proclamant la necessitat d'un aprofundiment democràtic (encara que no es va esbossar res molt més allà d'una reforma de l'actual modalitat delegacionista) i fent públic el mandat d'una Convenció amb l'expresident francés Giscard d'Estaing al capdavant.

Aquesta nova fita, la Convenció sobre el Futur d'Europa (2003), va desenvolupar els treballs previs al Tractat Constitucional i va apuntar a l'increment en el nivell de participació dels ciutadans europeus en el procés de presa de decisions. El rebuig a la Constitució Europea (2005) d'holandesos i francesos (entre altres), va obligar a una revisió que va culminar en el Tractat de Lisboa. Aquest últim, no obstant això, ha seguit la mateixa línia que la Convenció pel que fa a reforçar formalment el paper dels ciutadans, especialment a través de les «iniciatives ciutadanes» (article 11.4) (Bekemans, 2012).
Quant a l'anàlisi de contingut, el Tractat de Lisboa és similar a la Constitució Europea, perquè el primer sorgeix del braser de la segona i, per tant, el nombre total de paraules és similar i se situen com els textos de major volum, precisament pel seu caràcter omnímode. És lògic, per tant, que els lexemes analitzats tinguen una presència relativa menor, però en termes absoluts sí que permeten una anàlisi detallada. En l'associació a la identitat europea o a Europa, destaquen especialment, com en altres documents, la cultura i herència comunes, fins i tot exposades de manera combinada per a reforçar la base objectiva sobre la qual ha d'alçar-se l'edifici europeu («herència cultural comuna», «herència cultural de significació europea» com ja s'apuntava en el TEU). En la mateixa línia, la cultura s'associa també a la història («història i cultura dels europeus»). Molt significatiu ens sembla com arriba a adjectivar-se l'herència en la part II del Tractat Constitucional (TCE), referida a la Carta dels Drets Fonamentals, ja que es parla d'una «herència espiritual i moral» de la qual «n'és conscient la Unió», i que és la que exerceix del marc històric per al desenvolupament present i futur dels valors universals i democràtics de la UE. Fins i tot, més precisament, en el preàmbul parla de la «herència cultural, religiosa i humanista» que antecedeix aquests valors, en la qual és única referència explícita a la religió tant del TCE com del Tractat de Lisboa (TL) (encara que, mantenint el criteri del Tractat de Maastricht, s'obvia l'al-lusió directa al cristianisme).

Però, en el propòsit de detectar l'objectivació de la identitat europea, el TCE destaca de manera especial per la introducció explícita del camp simbòlic. En concret, el seu article I-8 sentència que els símbols de la UE són: la bandera amb el fons blau i les dotze estreles grogues, l'himne basat en l'Oda a l'Alegria de la Novena simfonia de Beethoven, el lema «Unitat en la diversitat», l'euro (i els seus elements arquitectònics impresos, anònims però recognoscibles en el marc de la cultura europea), i el 9 de maig com a Dia d'Europa. Aquesta és precisament una de les principals modificacions entre el TCE i el TL, ja que va ser eliminat del text final del TL i només 
inclòs com una declaració dels setze països que accepten el «sentit de comunitat» que hi ha darrere d'aquests símbols. Els altres dotze (bàsicament els països escandinaus i bàltics, i les illes britàniques, a més de Croàcia, França, Països Baixos, Polònia i la República Txeca) van assentar part del seu rebuig al text constitucional en la introducció d'aquests símbols, que podien erosionar la seua integritat nacional. Per tant, s'identificava en aquest cas, de l'una o l'altra manera, la tensió identitària entre el nou ens supranacional i els Estats nació: els passos per a reforçar la identitat europea en el pla aparentment trivial del simbòlic es veuen com una amenaça des d'algunes elits nacionals (encara que això també es manifesta en l'opinió pública de determinats països; veure Fligstein et ál., 2012).

$\mathrm{Al}$ costat d'aquesta alteració notòria, la presència d'expressions i lexemes que objectiven la identitat europea queda una miqueta rebaixada en el $\mathrm{TL}$, però es continua parlant de $\mathrm{l}^{\prime}$ «herència cultural, religiosa i humanista d'Europa» o fins i tot de la UE com «una societat», terme que havia desaparegut des que fora usat intensament en 1975 en l'Informe Tindeman. Per contra, el cicle que obri la Declaració Laeken i culmina en el Tractat de Lisboa, omet significativament el concepte «identitat europea» potser intentant esquivar les polèmiques que, de totes maneres, van ser avivades per la qüestió simbòlica.

Enfront de l'objectivació d'Europa o la UE, el TCE i el TL objectiven en major mesura la realitat estatal i de manera molt particular quan es refereixen en múltiples ocasions a la cultura o tradició dels Estats membres, que són elements a preservar. En el cas de la cultura, normalment com a part d'una diversitat que no ha de menyscabar-se en benefici de la hipotètica uniformitat que representaria la UE. I quant al segon lexema, són repetides les referències a les tradicions constitucionals dels Estats membres, normalment per a subratllar que són la font de la qual beu la normativa europea o que s'ha de respectar la seua singularitat (de fet, algunes de les presències de «tradició» en el TL es troben en les declaracions particulars annexes que realitzen estats com Txèquia o Irlanda, que són alguns que es van oposar al TCE). Així mateix, i enfront de la cridanera absència de la «identitat europea», s'alludeix en alguna ocasió a les «identitats nacionals», sempre per a precisar que el projecte comú no ha d'impedir que siguen respectades.

D'altra banda, i hipotèticament, la progressió en la definició de ciutadà europeu, les seues obligacions i drets, i l'ampliació del seu concurs en la presa de decisions (encara que seguisca en un nivell limitat) permeten modificar la relació entre ciutadà i nació, i obrin la possibilitat que es vagen assentant la identificació amb Europa i el desenvolupament d'una esfera pública europea, que és compatible amb el marc nacional i els sentiments de pertinença que genera (Bekemans, 2012; sobre l'impacte del marc jurídic comú, veure Carr, 2015). En definitiva, els valors que desenvolupen els tractats (llibertat, igualtat, pluralisme, tolerància, justícia, etc.) es pretén que siguen constitutius de la identitat europea. Però la retallada del text constitucional, en alguns casos quant al desenvolupament de la ciutadania europea, deixa en suspens la progressió de la identificació amb la UE, mentre que la que es produeix amb els Estats es manté gràcies als moviments defensius que es van gestar a principis de mil.lenni, i que quedarien consolidats amb la crisi (Přibáň, 2009: 48).

\section{BALANC}

Tot i que no hi ha canvis dràstics, perquè la tònica general és la primacia d'una concepció políticocívica combinada amb elements del tipus etnocultural, en el recorregut històric per aquests textos de les institucions europees podem identificar quatre fases:

1. Primitiva (dècades 50-60): no hi ha una preocupació excessiva per la identitat europea, $i$ es ve d'un moment en què políticament $i$ fins i tot acadèmicament domina una visió etnocultual de la identitat territorial (encara que també es considera la dimensió subjectiva). 
2. Focalització (dècades 70-80): inici d'una preocupació explícita per la identitat europea. Combinació de les concepcions políticocívica i etnocultural.

3. Assentament (dècada 90): la identitat com a qüestió central. Domini clar d'una concepció políticocívica, encara que persisteixen els elements objectius culturals.

4. Desplaçament (dècades 2000-10): es manté el domini de la concepció políticocívica amb presència d'elements culturals, però la identitat europea desapareix del focus, perquè entra en conflicte amb algunes identitats nacionals.

En suma, s'endevina un avanç gradual de la concepció políticocívica i hi ha una intenció sobre aquest tema en la línia d'incrementar el protagonisme de la cituadania per a guanyar en legitimitat, almenys formalment. Al mateix temps, la Unió Europea i en concret la seua identitat han experimentat reticències, quan no obert rebuig, per part de forces de tall nacional-estatal que han espentat per a fer desaparéixer dels textos oficials el concepte «identitat europea» i arraconar els símbols europeus (i amb ells la que anava a ser Constitució de la UE). Malgrat això, fins i tot en el Tractat de Lisboa, els elements que objectiven la identitat europea des d'un punt de vista cultural han seguit presents per a exercir de contrast amb un projecte i una concepció políticocívica. Si bé aquesta última guanya terreny, precisament la crisi de legitimitat de la UE, en part a causa d'un dèficit democràtic, a l'escàs pes dels ciutadans en la presa de decisions, impedeix que els seus ideals es mostren en tota la seua expressió. Mentrestant, els autors dels preàmbuls d'aquests tractats, com fa dècades, es veuen en la necessitat d'apuntalar objectivament la UE, la seua identitat, assumir públicament que hi ha una realitat històrica comuna (Tsaliki, 2007). I aquestes formulacions s'efectuen precisament per a combatre l'estigma de l'artificiositat de la construcció europea. Com abans ha succeït amb les nacions, hi ha una temptació recurrent de projectar una lectura perennialista que trasllade a l'imaginari públic un ens naturalitzat, amb una extensa continuïtat en el temps i l'existència del qual, per tant, s'explica per si mateixa, pel seu traçat històric.

Per tant i de facto, s'està produint una combinació dels diferents models de construcció identitària que plantejava Bekemans (2012), tant el comunitari, amb el seu èmfasi en elements culturals, com el liberal-republicà i la seua atenció a una mena d'identitat cívica, basada en els principis universals de la democràcia, els drets humans, la llei, etc. Però també el constructivista, perquè és un fet que s'està donant un increment dels intercanvis entre els europeus $i$, conseqüentment, la creació d'un espai compartit comença a cobrar forma a diferents nivells.

De totes maneres, la identitat europea està lluny del vigor de les identitats nacionals, dista de ser qualificable com una identitat «forta», en el sentit que va apuntar Cathleen Kantner (2006; veure també Přibáň, 2009: 44-45), i per això es fa difícil que aflore un sentit de ciutadania que permeta la solidaritat entre europeus. Així, per exemple, els alemanys no van sentir la necessitat de ser solidaris amb els grecs en 2010, segons es va poder veure en diverses enquestes a Alemanya, però el sentit de comunitat nacional sí que possibilitava la solidaritat amb els alemanys menys afavorits (Fligstein et ál., 2012), just en l'inici d'una era de minijobs en aquest país.

En qualsevol cas i prenent els arguments de Michael Billig (2006) sobre el «nacionalisme banal», els europeus, pel vincle legal als seus Estats, són ciutadans de la UE, tenen un mapa, una bandera, un himne, unes capitals, unes institucions, referències reiterades en els mitjans i els llibres de text, relativa consciència col-lectiva de pertànyer a la comunitat dels europeus, etc. La França de final del segle XVIII, un dels paradigmes del germen de la nació moderna, no tenia millors condicions per a convertir-se en nació que les que té Europa actualment per a passar a ser una «supranació». Així i tot, fan falta més elements per a construir eixa «identitat forta» però sobretot que la presència d'Europa en la vida dels ciutadans 
tinga un pes similar al de les nacions i Estats als quals pertanyen - possibilitant si no hi ha altre remei la gestació d'un «poble europeu» real (Tsaliki, 2007: 166; Přibáň, 2009: 44)—, i això no sembla que vaja a produir-se a curt o mitjà termini. Precisament el Brexit assenyala el camí de la involució en aquest sentit.
Queda pendent un nou tractat que actualitze el projecte tenint en compte els esdeveniments de l'última dècada i la necessitat imperiosa de democratització, requeriment sense el qual eixa identitat europea en la qual tenen tanta importància els drets universals i els valors cívics no tindrà capacitat de reimpuls.

\section{REFERÈNCIES BIBLIOGRÀFIOUES}

Adonnino, P. (1985). People's Europe. Reports from the ad hoc committee. Bulletin of the European Communities, 7.

Balanyà, B., Doherty, A., Hoedeman, O., Ma'anit, A., Wesselius, E. (2002). Europa S.A. Barcelona: Icaria.

Bekemans, L. (2012). The idea of Europe: Identity-building from a historical perspective. L. Bekemans (ed.), $A$ value-driven European future (pp. 65-81). Nova York: Peter Lang. https://doi.org/10.3726/978-3-0352-6233-9.

Billig, M. (2006). Nacionalisme banal. Catarroja: Afers-Universitat de València.

Carr, K. (2015). Regulating the periphery - shaking the core. European University Institute Working Papers, 40, 28 pp. https://dx.doi.org/10.2139/ssrn.2728671.

Català, L. (2012). Fonaments de la identitat territorial amb especial atenció a la identitat nacional. Alacant: Universitat d'Alacant (tesi doctoral).

Català, L., i Nieto, M. (2018). Identidad supranacional europea en un contexto de crisis. OBETS-Revista de Ciencias Sociales, 13(1), 15-43. https://doi.org/10.14198/OBETS2018.13.1.01.

Clerc, L. (2014). European identity: the past and the present. M. Holmberg i H-P. Ikäheimo (eds.), Narratives of Europe (pp. 7-13). Tallin: Eurooppalainen Suomi ry.

Comissió Europea (2012). The development of European identity/identities: unfinished business. Brussel-les: Comissió Europea.

Comissió Europea (1992). Tratado de la Unión Europea. Brussel-les: Comissió Europea.

Comissió Europea (1973). Declaration on European Identity. Bulletin of the European Communities, 12, 118-122.

Delanty, G. (2003). Is there a European identity? Global Dialogue, 5(3-4).

ETCD-European Task Force on Culture and Development (1997). In from the margins. Estrasburg: Consell d'Europa.

Etxezarreta, M. (2008). La evolución (perversa) de la política social de la Unión Europea. Revista Internacional de Filosofía Política, 31, 123-138.

Gellner, E. (1983). Nations and Nationalism. Ithaca (NY, US): Cornell University Press.

Ferreira, G. B. (2009). What identity for Europe? Social Science Tribune, 14(55), 13-28.

Fligstein, N. (2009). Euro-clash. Oxford: Oxford University Press. https://dx.doi.org/10.1093/ acprof:oso/9780199580859.001.0001.

Fligstein, N., Polyakova, A., Sandholtz, W. (2012). European integration, nationalism and European identity. Journal of Common Market Studies, 50(51), 106-122. https://doi.org/10.1111/j.1468-5965.2011.02230.x.

Friese, H. (2004). La otredad de Europa. Política y Sociedad, 41(3), 99-112.

Gattermann, K., Högenauer, A.-L., Huff, A. (2016). Studying a new phase of Europeanisation of national parliaments. European Political Science, 15(1), 89-107. https://doi.org/10.1057/eps.2015.56.

Granja, D. M., i Charpenel, E. (2014). El ideal de la paz perpetua en Rousseau y Kant. Signos Filosóficos, 16(31). https://doi.org/10.15446/ideasyvalores.v65n162.59715.

Guth, J. L., i Nelsen, B.F. (2014). Religion in the creation of European and national identities. Oxford Symposium on Religious Studies at the University. Church of St. Mary. Desembre.

Habermas, J. (1996). The European Nation State. Ratio Juris, 9(2), 125-137. 
Hernández, J., i Ramiro, P. (2016). Contra la lex mercatoria. Barcelona: Icaria.

Hobsbawm, E. J. (1992). Naciones y nacionalismo desde 1780. Barcelona: Crítica.

Hobsbawm, E. J., i Ranger, T. (Comps) (1988). L'invent de la tradició. Vic: Eumo.

Hopkins, D. J., i King, G. (2010). A method of automated nonparametric content analysis for social science. American Journal of Political Science, 54(1), 229-247. https://doi.org/10.1111/j.1540-5907.2009.00428.x.

Hroch, M. (1996). From national movement to the fully-formed nation. G. Balakrishnan (ed.), Mapping the nation (pp. 78-97). Londres: Verso.

Innerarity, D. (2013). The political innovation of the European Union. Cuadernos Europeos de Deusto, 48, 51-72. https://doi.org/10.1007/978-3-319-72197-2_7.

Innerarity, C., y Acha, B. (2010). Los discursos sobre ciudadanía e inmigración en Europa. Política y Sociedad, 47(2), 63-84.

Jansen, T. (ed.) (1999). Reflections on European Identity. Brussel-les: Comissió Europea.

Kaelberer, M. (2004). The Euro and European Identity. Review of International Studies, 30, 161-178. https://doi. org/10.1017/S0260210504005996.

Kantner, C. (2006). Collective identity as shared ethical self-understanding. European Journal of Social Theory, 9(4), 501-523. https://doi.org/10.1177/1368431006073016.

Karlsson, I. (1999). How to define the European identity today and in the future? T. Jansen (ed.), Reflections on European identity (pp. 63-72). Brussel-les: Comissió Europea.

Keating, A. (2009). Educating Europe's citizens. Citizenship Studies, 13(2), 135-151. https://doi. org/10.1080/13621020902731140.

López Facal, R. (2010). Nacionalismos y europeísmos en los libros de texto. La Historia Enseñada, 14, 9-30. https:// doi.org/10.14409/cya.v1i14.1673.

McDonald, M. (1999). European identity - an anthropoligical approach. T. Jansen (ed.), Reflections on European Identity (pp. 77-80). Brussel-les: Comissió Europea.

Moes, J. (2008). European identity compared. ECPR 4th Pan-European Conference on EU-Politics, 25-27, 23 pp.

Paradés, M. (2013). La identidad española y la identidad europea en el apoyo a la Unión Europea. XI ${ }^{\circ}$ Congreso Español de Sociología, July. FES, Madrid.

Popa, M-C. (2016). Algunas reflexiones sobre el análisis del proyecto europeo como espacio discursivo. Espéculo, $56,9-16$.

Přibáň, J. (2009). The juridification of European identity. Constellations, 16(1), 44-58. http://dx.doi.org/10.1111/ j.1467-8675.2009.00520.x.

Recchi, E., i Salamo囚ska, J. (2014). Keeping the European faith. Partecipazione e Conflitto, 7(3), 509-531. https://doi. org/10.1285/i20356609v7i3p509.

Smith, A. D. (2004). Nacionalismo. Madrid: Alianza Editorial.

Trausch, G. (1999). Consciousness of European Identity after 1945. T. Jansen (ed.), Reflections on European identity (pp. 21-26). Brussel-les: Comissió Europea.

Tsaliki, L. (2007). The construction of European identity and citizenship through cultural policy. European Studies, 24, 157-182. https://doi.org/10.1163/9789401204156_010.

Waldschmidt, A. (2009). Disability policy of the European Union: the supranational level. ALTER-European Journal of Disability Research, 3, 8-23. https://doi.org/10.1016/j.alter.2008.12.002.

Westle, B. (2016). National and European Identity. J. Grimm, L. Huddy, P. Schmidt, J. Seethaler (Eds.). Dynamics of National Identity (pp. 256-283). Nova York: Routledge.

Wisniewski, E. (2013). The influence of the European Parliament on the European External Action Service. European Foreign Affairs Review, 18(1), 81-102.

Wodak, R., i Boukala, S. (2015). European identities and the revival of nationalism in the EU. Journal of Language and Politics, 143, 87-109. https://doi.org/10.1075/jlp.14.1.05wod. 


\section{NOTA BIOGRÀFICA}

Doctor en Sociologia per la Universitat d'Alacant. Durant més de 20 anys consultor al mateix temps que professor associat en la Universitat d'Alacant, des de 2018 és professor a temps complet en el Departament de Sociologia II. Les seues línies d'investigació principals són: identitat, sociolingüística i sociologia de l'alimentació. 